\title{
A Customized Grade Evaluation and Student Retention System (GESRS) for a Philippine State University
}

Karen W. Cantilang*

Department of Information Technology, Eastern Samar State University, Philippines; ayencantilang@gmail.com

\begin{abstract}
Objectives: This study focused on the development of a Customized Grade Evaluation and Student Retention System (GESRS) for Eastern Samar State University, a state university located in Eastern Samar, Philippines. The major functions of the system are (a) monitoring of student's retention status and (b) evaluation of student's grade. Methods/Statistical Analysis: This study adapted the Developmental - Evaluative research design. The researcher developed a system using the Iterative Development Model. The system was evaluated using two (2) sets of questionnaires. The first questionnaire adopted metrics from the ISO 9126 Software Product Quality Model. The second questionnaire used the IBM Computer Usability Satisfaction Scale. Findings: After the rigorous development, the researcher was able to incorporate the following restores into the system: (a) Student grade evaluation with student retention (b) reports generation of students with student retention status (c) grade adding, uploading and updating module for instructors. The expert testing resulted to a mean of 4.50 for reliability, 4.68 for usability, 4.73 for efficiency, 4.60 for maintainability, and 4.64 for portability, all were interpreted as highly functional, highly reliable, highly usable, highly efficient, highly maintainable and highly portable respectively. This means that the system was free from errors, easy to use, has proper data management and can be transported from one computer system to another easily. The End-user testing recorded a high rating for question 6, 1, and 2 respectively. This only means that the end-users found the system easy to use, was satisfied with the over-all look of the system and found the simple button and module orientation of the system easy to navigate. It was also evident in the results that they were able to finish their tasks using the system. Application and Improvements: The successful development of the system will pave way to the successful implementation of the retention policy of the university and will further enhance the monitoring of student grades and retention status.
\end{abstract}

Keywords: Automation, Information System, Retention, Student Evaluation, Student Grade

\section{Introduction}

Eastern Samar State University (ESSU) is a multi-campus university and is considered as the leading university in the entire island of Samar. As the university keeps booming, the course offers expanded as well as the population of the students, making it difficult to monitor the academics of the students. One of the issues that arise is the monitoring and implementing the retention policy of the university. Retention is defined in the Galway-Mayo Institute of Technology (GMIT) Student Retention Policy as the ability of the Institute to retain students so that they can progress through the different stages of their program of study.

It is staying in a school or in an institution until completion of a program or a degree and is determined by the student's academic performance, particularly, based on the student's grades gained every after semester or summer term ${ }^{1}$.

${ }^{*}$ Author for correspondence 
Recently, ESSU adapted a computerized school management system, but the university does not include a system or mechanism to monitor the implementation of the retention policy as provided in the University's Operations Manual for Academic Affairs. This scenario allows students with failing grades to continue their studies and enroll in the university with the full academic load without the registrar's office noticing it. The issue on students' retention and academic deficiencies are only detected right before or during the application for graduation causing a heartbreaking scenario to student applicant and their parents. It does not only have an impact on the student and his family but also produce a ripple effect on the academic institution. It is important that higher education providers, such as ESSU, shall address various challenges in supporting students on their academic journey. Thus, the researcher was prompted to develop a Customized Grade Evaluation and Student Retention System (GESRS) for Eastern Samar State University in an attempt to address and further understand the challenges related to the retention policy of the University.

\section{Objectives of the Study}

This study aimed to develop a web-based Student Grade Evaluation with Retention System for Eastern Samar State University. Specifically, this study aimed to achieve the following:

\section{Develop a system that:}

a) Allow the students to evaluate or view their grades and their retention status.

b) Generate reports or lists of students with retention status (e.g. Warning, probation and dismissal).

c) Allow the university instructors to add or upload and update the grades of the student(s) under the subject that they are handling.

2. Evaluate the system using the ISO 9126 Software Product Quality Model for expert testing and IBM Computer Usability Satisfaction Questionnaire for the end user testing.

\section{Software Development Model}

The researcher adopted the Iterative Model in the development of this study because it starts from simple requirements and gradually increases the features and requirements as the development progresses. That means that the Iterative Model is adaptable to the ever-changing needs of the project, so any new and misunderstood requirements could be implemented during the development of the system. This type of development model also allows the identification of design and functional flaws which works as an advantage to the researchers in performing corrective measures as early as possible before the actual implementation of the system. The Iterative model is also applicable in developing a system where there is a time constraint which suits with the development period and schedule of the researchers ${ }^{2}$.

Figure 1 shows how the Iterative model starts with planning phase where preliminary observations are done then iterates the analysis design, and implementation phase to produce the best version of the system.

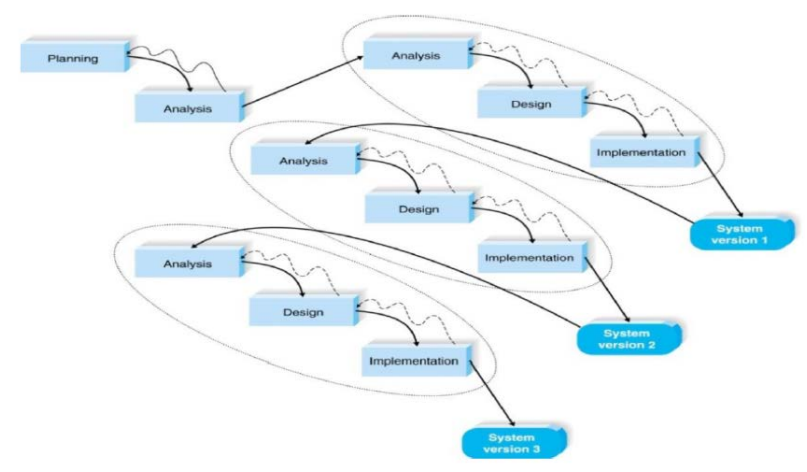

Figure 1. Iterative model ${ }^{2}$.

\section{Use Case Diagram}

Figure 2 shows the processes the users can perform using the system. There are four (4) actors of the system namely the registrar, instructor, student, and the web server. The registrar has all the authority or access on the system. While the instructor can only enter the grades of the students. And the students can only view their grades in this system. The instructor can choose to manually enter the grade or upload a grade sheet in excel file format. Before the students can view their grades the registrar should validate the uploaded grade sheet. Once all the grades are completed the system will automatically generate retention status of the student. The web server provides the display or the GUI where the user interacts with the system.

\section{System Evaluation}

Two (2) sets of questionnaires were used in the evaluation of the system. The researchers used a questionnaire 
that adopted metrics from the ISO 9126 Software Product Quality Model. The questionnaire focused on evaluating the system in terms of its functionality, reliability, usability, efficiency, maintainability, and portability. The questionnaire was given to experts who were chosen because of their expertise in the field of web development and programming. The second questionnaire used the IBM Computer Usability Satisfaction Scale. The questionnaire focused on evaluating the systems' overall usability. It was given to the end users of the system particularly registrar personnel, instructors and students.

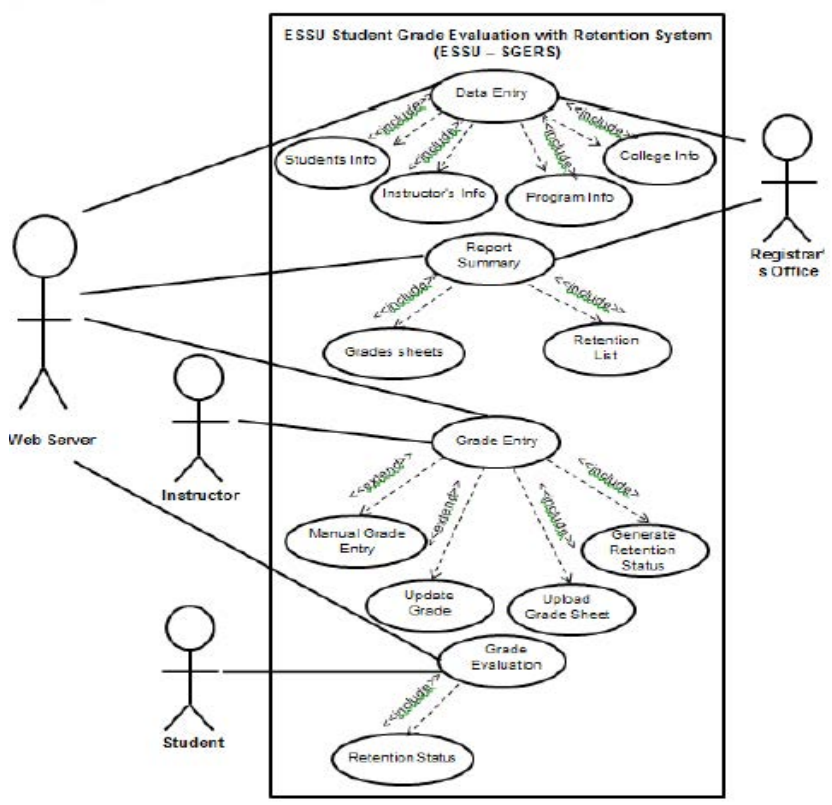

Figure 2. Grade evaluation and student retention system use case diagram.

\section{Graphical User Interface}

The following figures show the final design of the developed system.

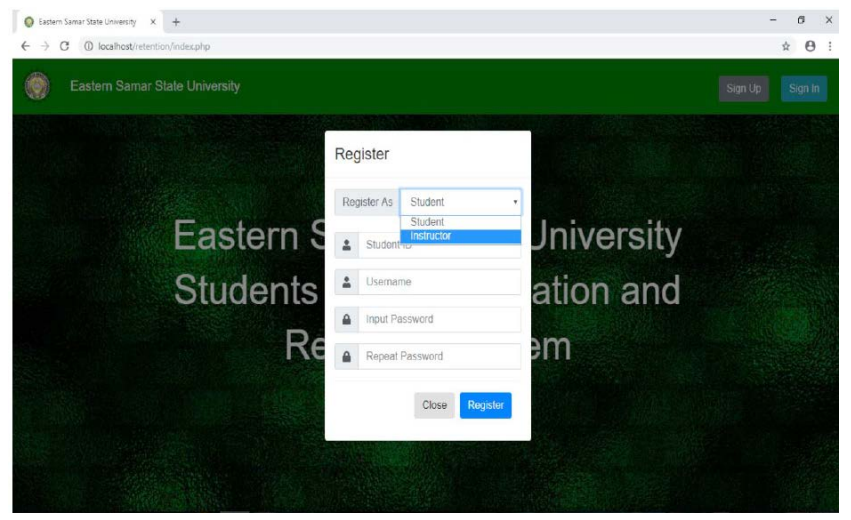

Figure 3. Registration form.
Figure 3 shows the form for registering into the online system. Students as well as the university instructors, are required to fill out the form so they can access the online system. Only students and instructors with an existing account can register into the online system.

Figure 4 shows the home page in the administrator. In this page, the user can navigate through the different forms and pages using the menu options on the left side of the page. There is also a shortcut navigation to specific pages located on the center of the screen. There is also a user account option located at the top - right side of the page and the user manual or information icon next to it.

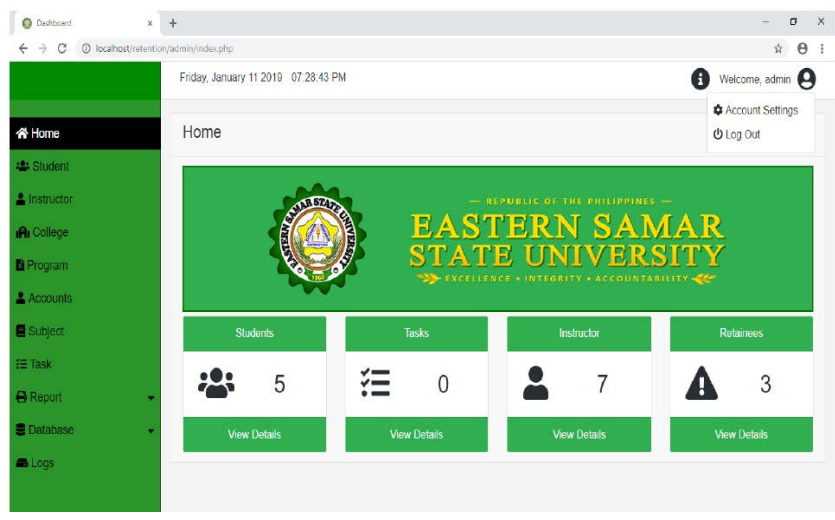

Figure 4. Administrator account: Home menu option.

Figure 5 shows the student menu option in the administrator account. This form also shows the list of students enrolled in the university.

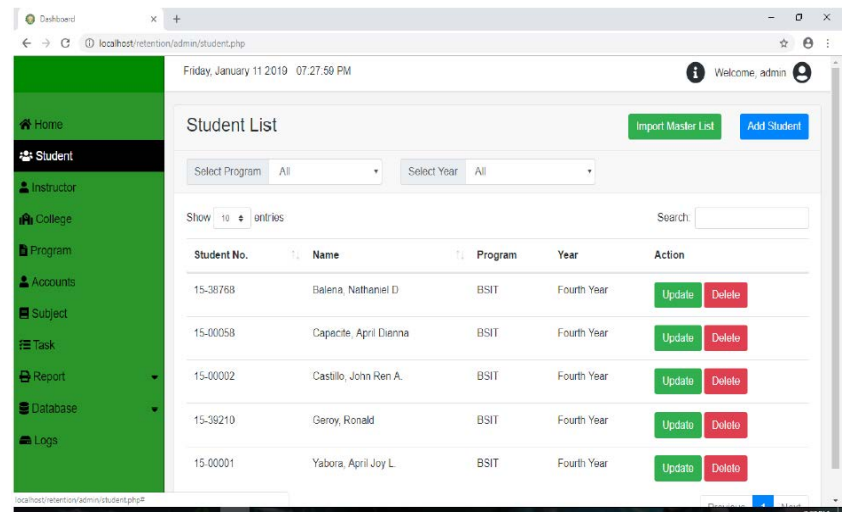

Figure 5. Administrator account: Student menu option.

Figure 6 shows the form for adding new student one by one or manually into the online system under the student menu option in the administrator account.

Figure 7 shows the form for importing master lists of students into the online system under the student menu option in the administrator account. 


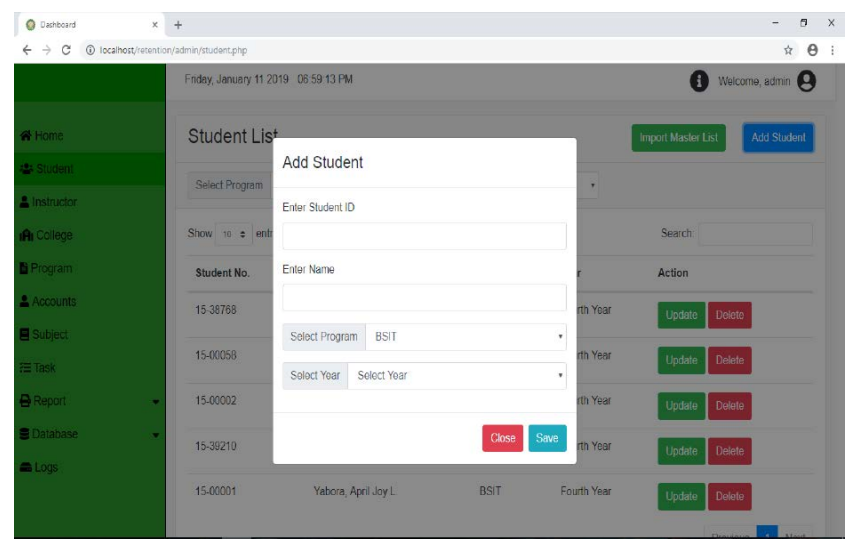

Figure 6. Student menu option: Add student form.

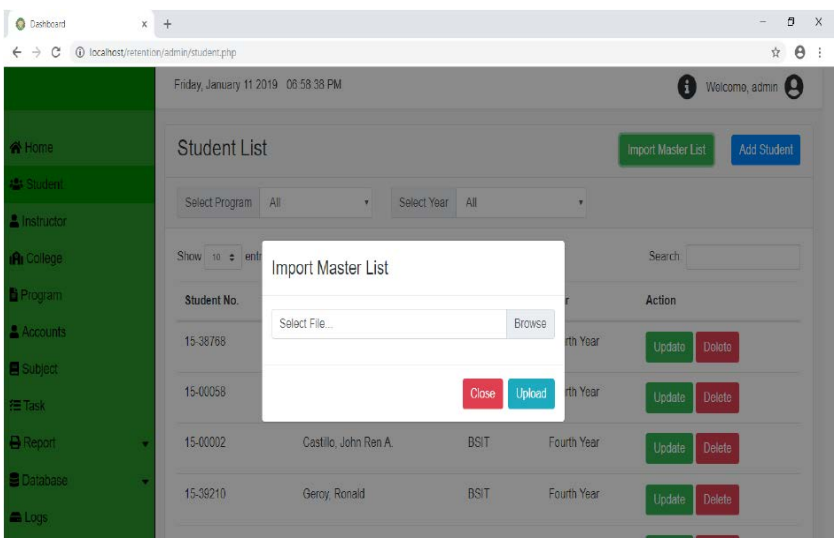

Figure 7. Student menu option: Import master list form.

Figure 8 shows the list of a registered instructor from different colleges. The administrator has the authority to add, update and delete the instructor's information.

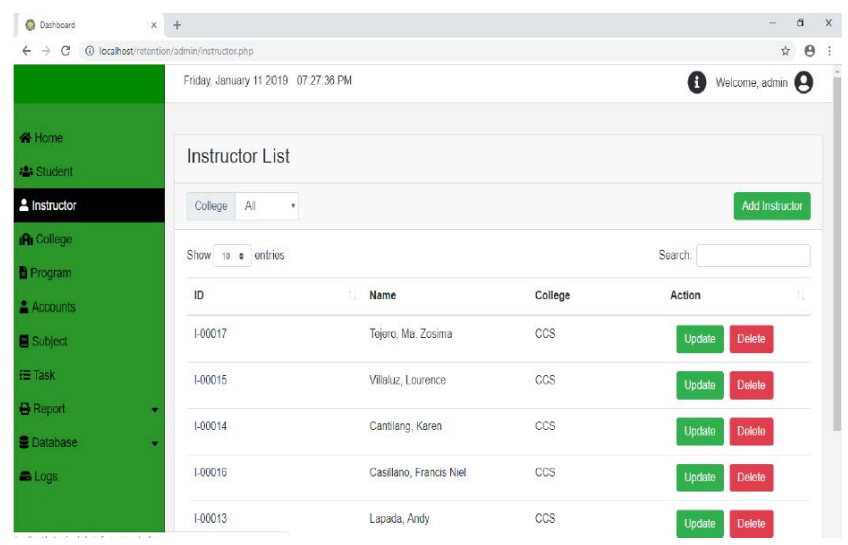

Figure 8. Administrator account: Instructor menu option.

Figure 9 shows the list of registered colleges in the system. The administrator has the authority to add new college, update current information and delete a college.

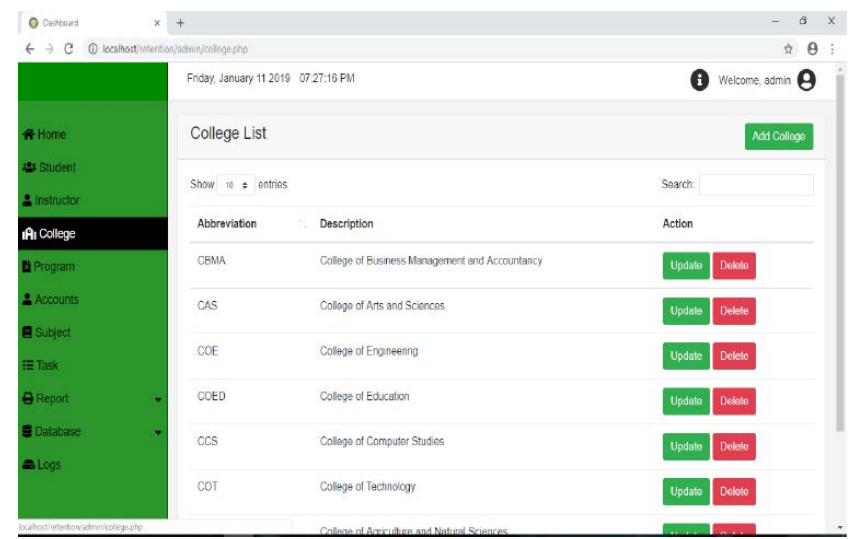

Figure 9. Administrator account: College menu option.

Figure 10 shows the screenshots of program menu wherein the administrator can view the lists of a registered program in every college. The administrator can choose to add a new program, update the information or delete a program.

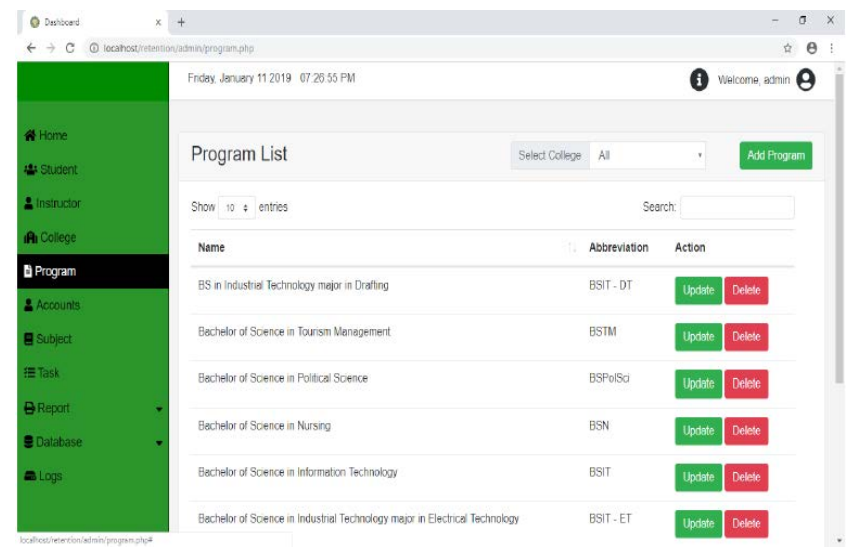

Figure 10. Administrator account: Program menu option.

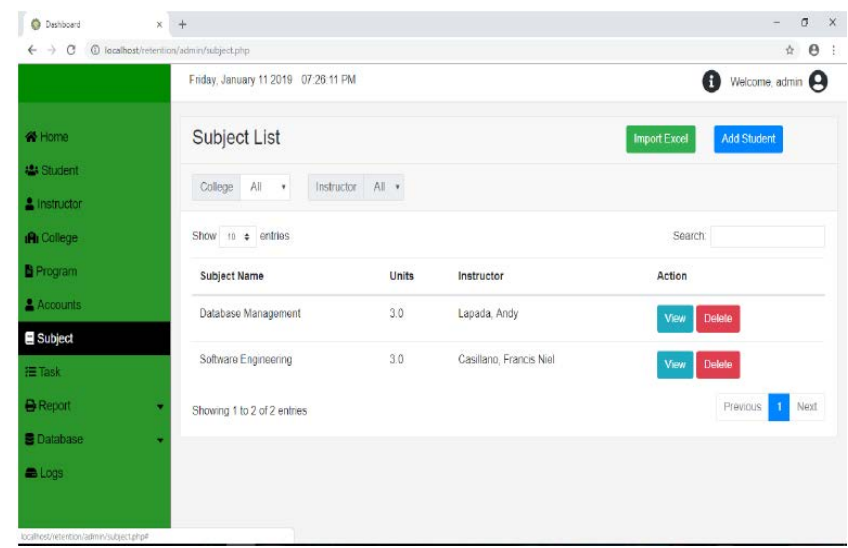

Figure 11. Administrator account: Subject menu option. 
Figure 11 shows the list of the lists of subjects handled by the different instructors under the subject menu option.

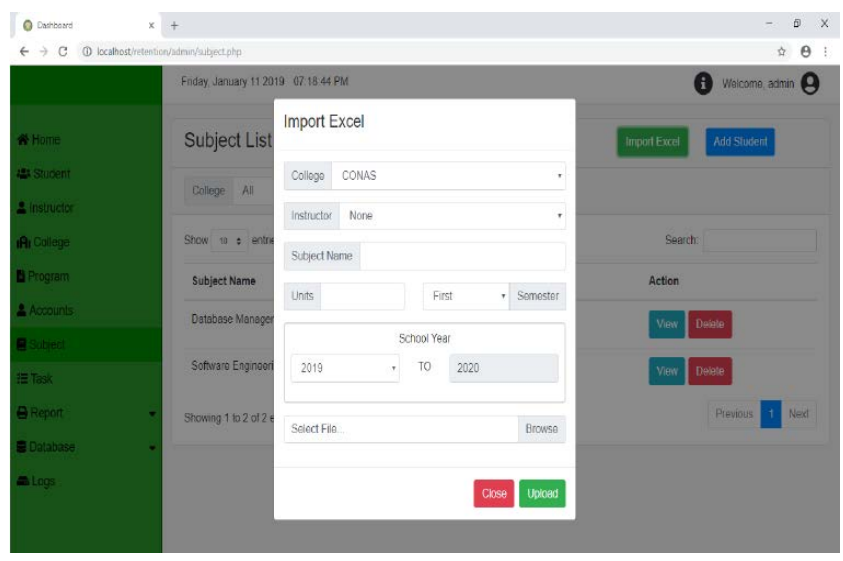

Figure 12. Subject menu option: Import excel form.

Figure 12 shows the form for importing a master list to enroll students in the subject and assign an instructor to handle the subject.

Figure 13 shows the list of pending grade sheets that needs approval or verification from the administrator.

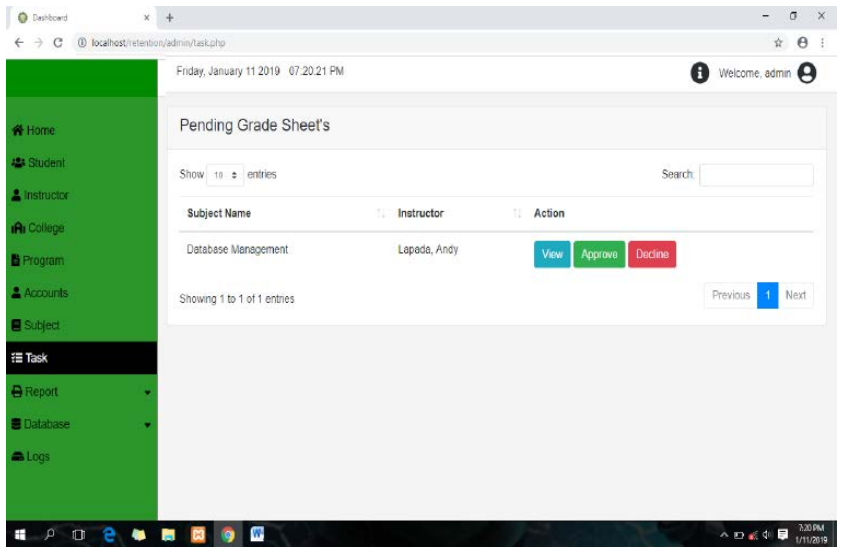

Figure 13. Administrator account: Task menu option.

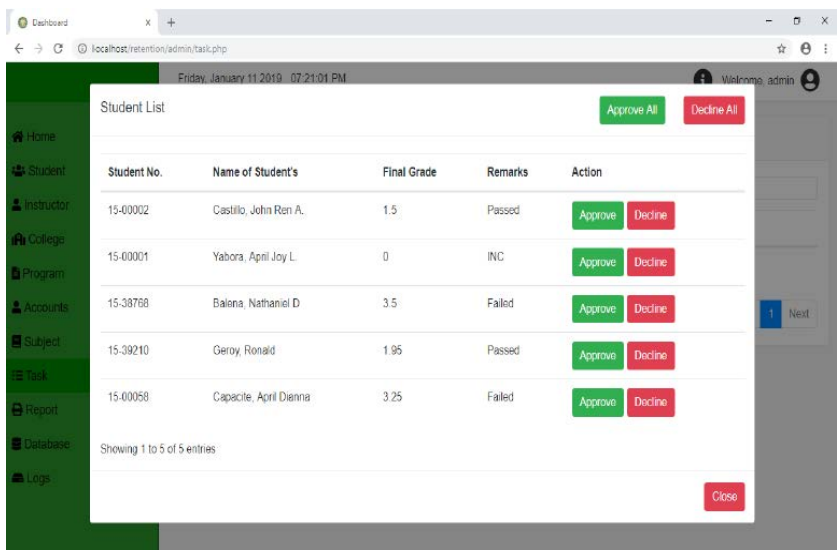

Figure 14. Task menu option: View task.
Figure 14 shows the view option in the task menu. The administrator can view the grades of the enrolled students and the administrator can either approve or decline students individually, or approve all or decline all pending submitted grades.

Figure 15 shows the screenshot of retention lists where the administrator can view the list of students with retention status.

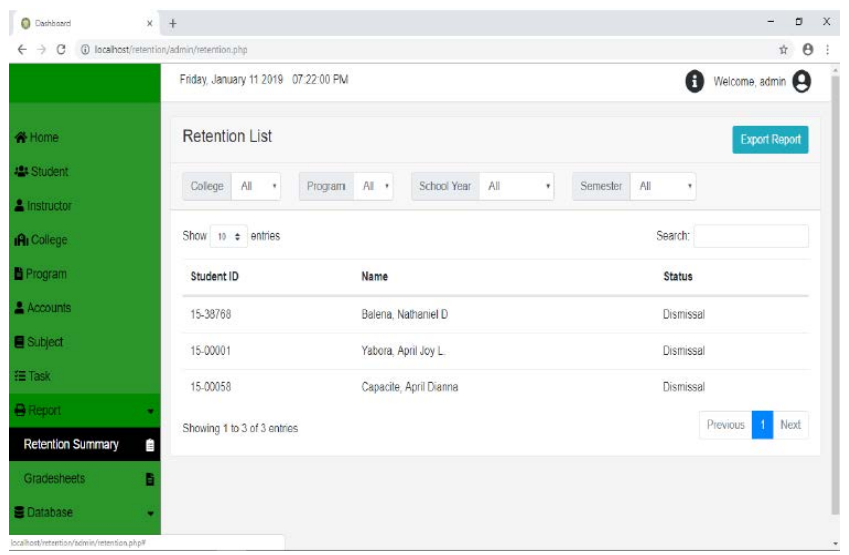

Figure 15. Report menu option: Retention summary.

\section{Software Evaluation Results}

Table 1. Expert testing results

\begin{tabular}{|l|l|l|}
\hline $\begin{array}{l}\text { ISO 9126 } \\
\text { Parameters }\end{array}$ & Weighed Mean & Interpretation \\
\hline Reliability & 4.50 & Highly Reliable \\
\hline Usability & 4.68 & Highly Usable \\
\hline Efficiency & 4.73 & Highly Efficient \\
\hline Maintainability & 4.60 & $\begin{array}{l}\text { Highly } \\
\text { Maintainable }\end{array}$ \\
\hline Portability & 4.64 & Highly Portable \\
\hline
\end{tabular}

Table 1 shows the summary of the results and the adjectival interpretations during Expert Testing. The testing resulted in a weighted mean of 4.50 for reliability interpreted as highly reliable, which means that the data management of the system was consistent and free from errors. For usability, the testing resulted to a weighted mean of 4.68 interpreted as highly usable, this means that the experts were able to accomplish the given tasks using the system and found the interface easy to use. For efficiency, the testing resulted in a weighted mean of 4.73 interpreted as highly efficient, which pertains that the system processing time is short and produces date fast. For 
Table 2. End user testing results

\begin{tabular}{|l|l|l|l|l|l|}
\hline Questions & S & I & R & Mean & Interpretation \\
\hline 1. I am satisfied with how easy it is to use this system. & 4.60 & 4.60 & 4.80 & 4.62 & Highly Usable \\
\hline 2. It was simple to use this system. & 4.80 & 4.60 & 4.60 & 4.62 & Highly Usable \\
\hline 3. I can effectively complete the tasks using this system. & 4.60 & 4.60 & 4.60 & 4.60 & Highly Usable \\
\hline 4. I am able to complete my work quickly using this system. & 4.60 & 4.60 & 4.60 & 4.60 & Highly Usable \\
\hline 5. I feel comfortable using this system. & 4.30 & 4.40 & 4.80 & 4.36 & Highly Usable \\
\hline 6. It was easy to learn to use this system. & 4.80 & 4.40 & 4.60 & 4.74 & Highly Usable \\
\hline $\begin{array}{l}\text { 7. Whenever I make a mistake using the system, I recover easily } \\
\text { and quickly. }\end{array}$ & 4.60 & 4.00 & 4.20 & 4.50 & Highly Usable \\
\hline $\begin{array}{l}\text { 8. The organization of information on the system screens is } \\
\text { clear. }\end{array}$ & 4.30 & 4.40 & 5.00 & 4.38 & Highly Usable \\
\hline 9. The interface of this system is pleasant. & 4.30 & 4.40 & 4.80 & 4.36 & Highly Usable \\
\hline 10. I like using the interface of this system. & 4.00 & 4.40 & 4.80 & 4.12 & Usable \\
\hline 11. Overall, I am satisfied with this system. & 4.50 & 4.40 & 5.00 & 4.54 & Highly Usable \\
\hline Grand Mean: & $\mathbf{4 . 4 9}$ & $\mathbf{4 . 4 4}$ & $\mathbf{4 . 7 1}$ & $\mathbf{4 . 5 1}$ & Highly Usable \\
\hline Legend: S - Student I - Instructor R - Registrars Employee & & & & & \\
\hline
\end{tabular}

maintainability, the testing resulted in a weighted mean of 4.60 interpreted as highly maintainable, which infers that the system can easily be fixed.

For portability, the testing resulted in a weighted mean of 4.64 interpreted as highly portable which means that the system being made using a web platform can be exported from one computer system to another easily.

Table 2 shows the evaluation results for End User Testing. The table shows a high rating for question 6,1 , and 2 respectively. This only means that the end-users found the system easy to use, was satisfied with the overall look of the system and found the simple button and module orientation of the system easy to navigate. It was also evident in the results that they were able to finish their tasks using the system.

\section{Conclusions}

With the primary aim to solve the existing problem of Eastern Samar State University in the implementation of their retention policy, the researcher developed an automated system capable of monitoring student's retention status. The system contained the following features (a) Student grade evaluation with student retention (b) reports generation of students with student retention status (c) grade adding, uploading and updating module for instructors. The expert testing resulted in a weighted mean of 4.50 for reliability interpreted as highly reliable, which means that the data management of the system was consistent and free from errors. For usability, the testing resulted to a weighted mean of 4.68 interpreted as highly usable, this means that the experts were able to accomplish the given tasks using the system and found the interface easy to use. For efficiency, the testing resulted in a weighted mean of 4.73 interpreted as highly efficient, which pertains that the system processing time is short and produces date fast.

For maintainability, the testing resulted in a weighted mean of 4.60 interpreted as highly maintainable, which infers that the system can easily be fixed and maintained. For portability, the testing resulted in a weighted mean of 4.64 interpreted as highly portable which means that the system being made using a web platform can be exported from one computer system to another easily. The Enduser testing recorded a high rating for question 6,1 , and 2 respectively. This only means that the end-users found the system easy to use, was satisfied with the over-all look of the system and found the simple button and module orientation of the system easy to navigate. It was also evident in the results that they were able to finish their tasks using the system.

\section{References}

1. Student Retention Policy [Internet]. [cited 2015]. Available from: https://www.auckland.ac.nz/en/about/the-univer- 
sity/how-university-works/policy-and-administration/ teaching-and-learning/general/student-retention-policy. html.
2. Systems Analysis and Design [Internet]. [cited 2008]. Available from: https://dl.acm.org/citation. cfm?id=1524120. 